\title{
Application of impact analysis SDC method for verification of whiplash injuries
}

\begin{abstract}
Piotr Aleksandrowicz ${ }^{1, *}$
${ }^{1}$ Machine Maintenance Department, Institute of the Automation and Transport, University of Science and Technology, Al. prof. S. Kaliskiego 7, 85-796, Bydgoszcz, Poland

Abstract. Collisions of vehicles that occur in cities involve relatively low speeds. Even though the speed of a collision is not high passengers are exposed to a risk of neck spine damage when a rear-end accident takes place. These injures are referred to as Whiplash injuries which are difficult to verify when it is necessary to resolve a rear-end collision damage claim. This study presents procedures of SDC method to be used for verification of circumstances that are reported to have caused such injuries. An analysis was carried out based on a case study of a collision of two passenger cars of different categories and the results can be used by theoreticians and practitioners who are involved in research on this subject.
\end{abstract}

\section{Introduction}

Although development of motorization has certainly a positive impact on the economic growth, and mobility of people, it has also negative effects.

In towns the volume of traffic is increasing which involves congestion and a higher risk of collision. Rush and lack of concentration of drivers contributes to accidents with participation of a vehicle - human - environment (V-H-E). Mutual relations and dependencies between people involved in this process are presented in Fig. 1.

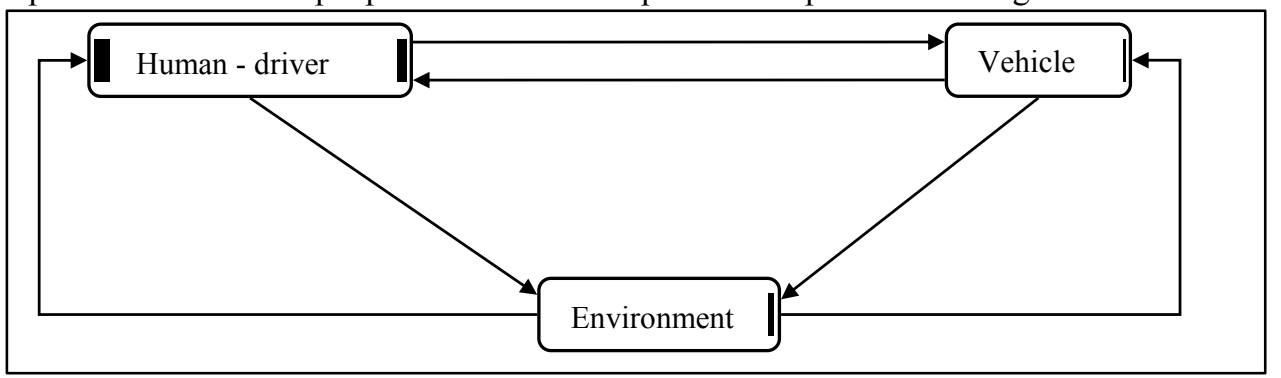

Fig. 1. H-V-E system [1].

The most important elements that affect safety of road traffic referred to the H-V-E system include:

$>$ humans - knowledge, skills, concentration, etc.,

$>$ environment - road infrastructure, traffic volume, road signs, etc.,

$>$ vehicle - dimensions, mass, impact resistance, car body deformability and its passive safety devices, etc.

Collisions classified according to a vehicle damage localization and the impact direction are presented in Fig. 2 and those depending on the impact angle in Fig. 3.

*Corresponding author: paleksandrowicz@utp.edu.pl 


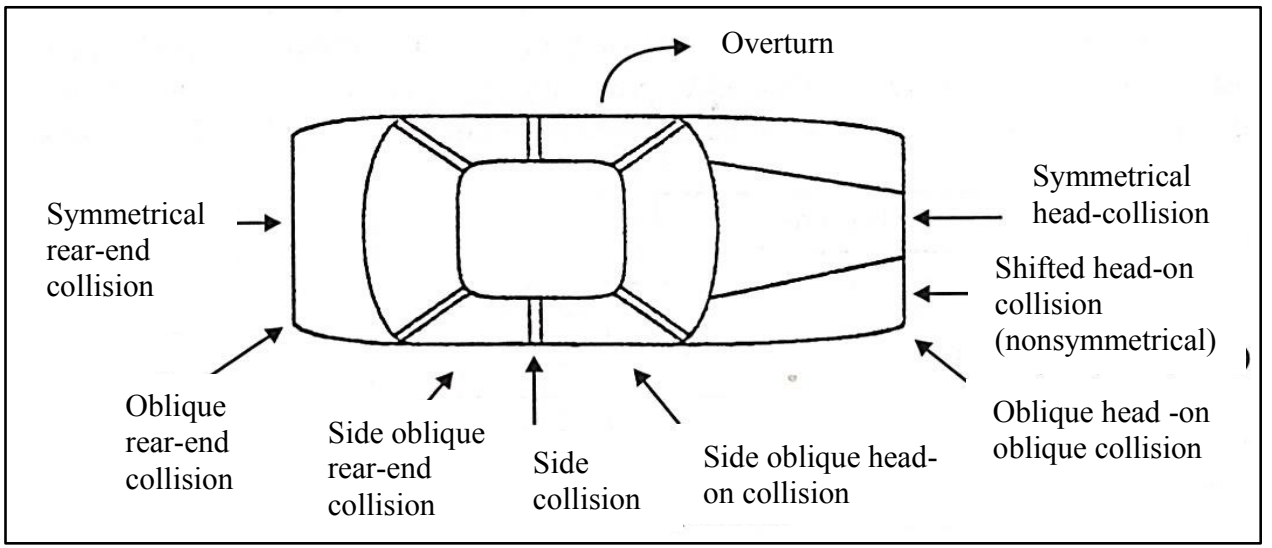

Fig. 2. Classification of impacts according to their localization [2].

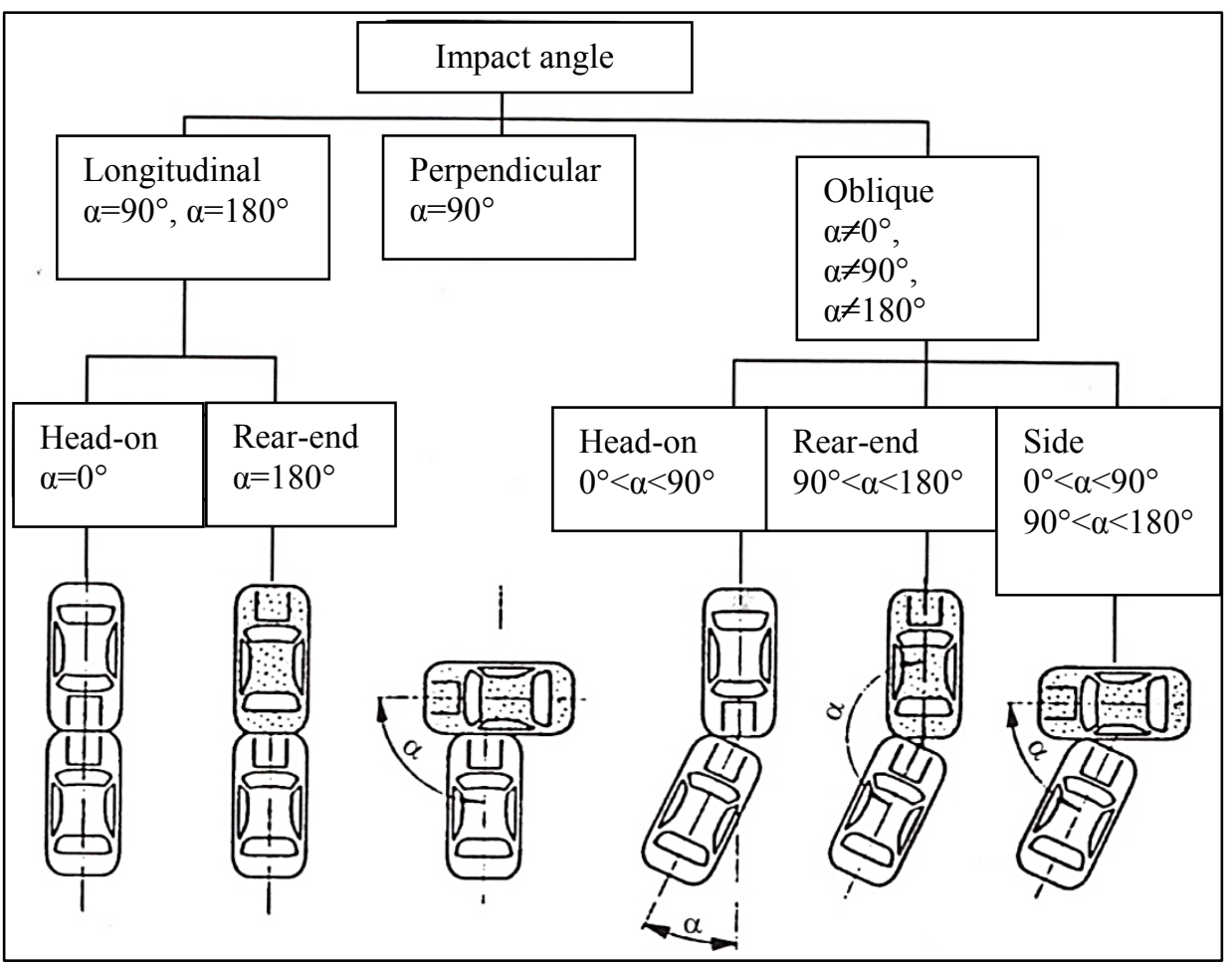

Fig. 3. Definition of the impact angle [2].

Head-on collisions are the most dangerous ones, whereas rear-end collisions are considered as the least serious. This results from the speed of the involved vehicles. Therefore, head-on crashes focus more attention than the rear-end ones. For example, work [3] includes an analysis of three different types of bumper beams of vehicles involved in crashes with different obstacles. Based on the obtained results, the authors selected a beam with the best characteristics for impacts involving low collision speeds. However, rear-end accidents, despite relatively low collision speeds, can also cause serious injuries to the neck due to rapid longitudinal forces acting forward from the vehicle back when safety devices fail to provide full protection from these injuries. 
This kind of spine injury is referred to as a Whiplash injury. In literature it is also called WAD (Whiplash Associated Disorders), Neck Injury, etc. Fig. 4 shows a mechanism of the above-mentioned injury occurrence.

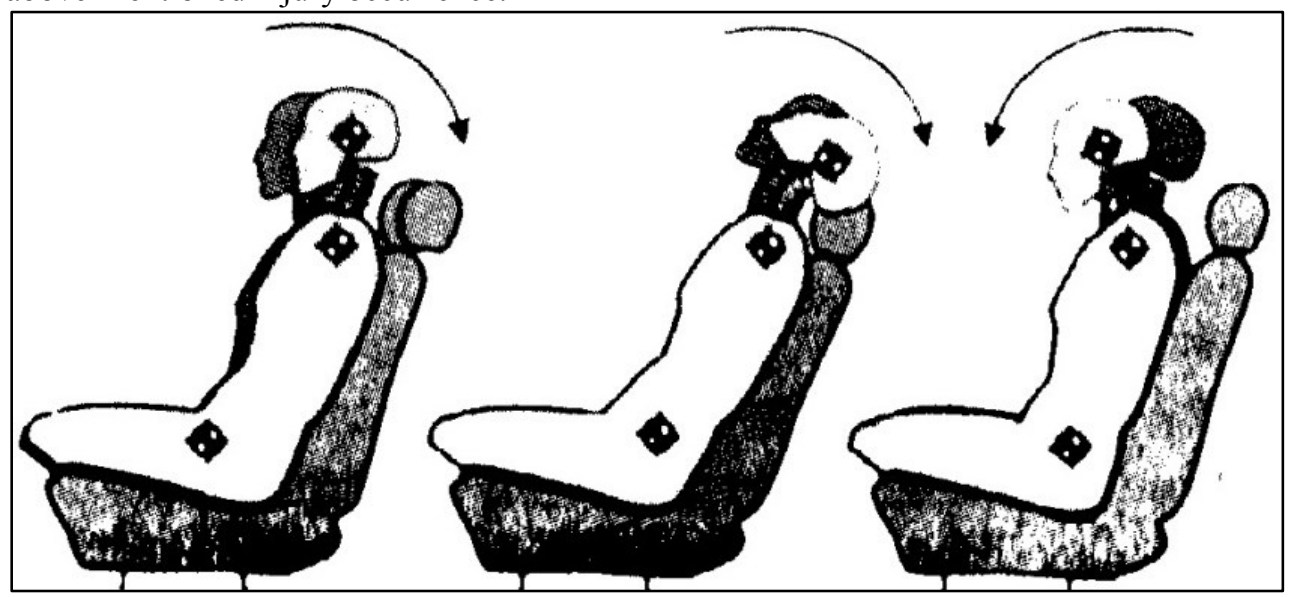

Fig. 4. Whiplash injury occurrence mechanism [4].

In practice, it is very difficult to verify claims involving whiplash injuries as it requires application of methods and tools enabling an analysis of many variables and criteria. A limited amount of input data is a significant barrier in verification of traffic claims.

\section{Research tools and procedures}

SDC method (Static, Dynamic, Characteristic analysis) has been proposed to verify an impact and Whiplash injury occurrence probability.

\subsection{Probability criteria for Whiplash injury occurrence}

Mechanism of Whiplash injury occurrence involves a rapid back and forth movement of the neck. This kind of injury causes persistent pain and can also lead to permanent physical disorder. These injuries affect the spine bones and the, so called intervertebral spaces. It was also noticed that chronic pain can occur without backward head movement in the direction to the headrest. In this case the injury can be caused by simultaneous parallel backward movement of the head which also affects the spine. Fig. 5 shows intensity of Whiplash injury in a function of time.

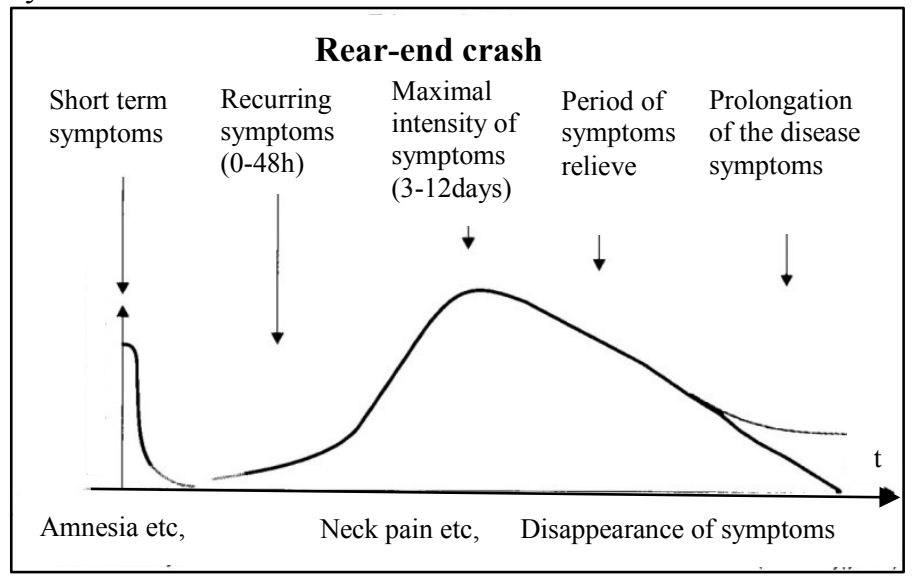

Fig. 5. Intensity of Whiplash injury in a function of time [4]. 
External criteria of Whiplash injury occurrence probability [4]:

$>$ relative speed of the hitting and hit vehicles was higher than $11 \mathrm{~km} \cdot \mathrm{h}^{-1}$,

$>$ mean acceleration of the hit vehicle exceeded $3 g$ or acceleration of the passenger or driver upper body part inside the vehicle exceeded $6 g$.

\subsection{Research procedures of SDC method}

Verification of an impact by SDC method requires three research procedures. The first one involves a static analysis of the damage to the vehicles involved in the accident. This procedure is supposed to provide geometric verification of the vehicle damage. The research methods of this procedure are discussed, among others, in work [5], where an analysis of an impact of a truck tractor with a passenger car is presented.

The second procedure uses computer devices for dynamic analysis of road accident reconstruction. It requires solution of problems involved in an impact modeling which are described, for example, in work [6]. This procedure applies simulation programs to perform analyses. Programs which model car accidents in MBS convention (Multi Body System) are most commonly used in practice. This modeling is, however, simplified and an expert needs to change many of the program parameters. For example, in works $[7,8,9]$ the authors, after identification of the impact parameters on the basis of a crash test, present sensitivity of the simulation parameters to be used for reconstruction of the crash according to initially accepted input data which causes simplification of modeling the forces that occur during the vehicle collision provided by the simulation programs. In Poland the most popular program used for impact modeling in MBS convention is V-SIM4 program. It is also used for simulation tests of, among others, the influence of selected defects of the braking system on the possibility to stop the car and on the impact effects which is described in works $[10,11]$. These works provide a description of modeling the movement of a vehicle with defects of a braking system with the use of V-SIM4 program in dependence on the brake shoes wear degree.

The third research procedure involves an analysis of characteristic damage in the site of the objects contact which was caused during the impact, for example pieces of paint, traces of wheels, etc. Occurrence of this kind of marks is accompanied by complicated phenomena which are described and analyzed, among others, in work [12]. This work includes information about how such marks occur during an impact of cars and provides the possibilities of practical applications of the results of carried out research.

\section{Research objects and parameters of the movement environment}

Research objects were passenger cars Mercedes class E of third generation and Citroën C1. The most important technical data of the cars and parameters of the movement environment accepted for simulation calculations are presented in table 1 .

Table 1. Technical data of research objects and parameters of the movement environment.

\begin{tabular}{|c|c|c|}
\hline Parametr & Citroën & Mercedes \\
\hline Vehicle curb weight & $875 \mathrm{~kg}$ & $1351 \mathrm{~kg}$ \\
\hline Driver weight & $75 \mathrm{~kg}$ & $75 \mathrm{~kg}$ \\
\hline Vehicle length/ width & $3.435 \mathrm{~m} / 1.630 \mathrm{~m} / 1.470 \mathrm{~m}$ & $4.740 \mathrm{~m} / 1.740 \mathrm{~m} / 1.430 \mathrm{~m}$ \\
\hline Wheelbase & $2.340 \mathrm{~m}$ & $2.800 \mathrm{~m}$ \\
\hline
\end{tabular}




\begin{tabular}{|c|c|c|}
\hline $\begin{array}{c}\text { Vehicle brake } \\
\text { efficiency }\end{array}$ & $8.2 \mathrm{kN}$ & $16.3 \mathrm{kN}$ \\
\hline ABS & YES & No \\
\hline Dry asphalt road & $\begin{array}{c}\text { adhesive friction coefficient } \\
\mu_{1}=0.8 \\
\text { slip friction coefficient } \\
\mu_{2}=0.75\end{array}$ & $\begin{array}{c}\text { adhesive friction coefficient } \\
\mu_{1}=0.8 \\
\text { slip friction coefficient } \\
\mu_{2}=0.75\end{array}$ \\
\hline $\begin{array}{c}\text { Rolling resistance } \\
\text { coefficient }\end{array}$ & 0.015 & 0.015 \\
\hline
\end{tabular}

\section{Case study - own research}

The verification was performed according to SDC method. Vector silhouettes of the vehicles were used for comparison of geometric location of the vehicles, Fig. 6. They are in the same scale and provide accurate shapes of the vehicle bodies (https://www.autoview.at). Results of measurements carried out according to the vector silhouettes confirmed overlapping of the vehicle damage zones.

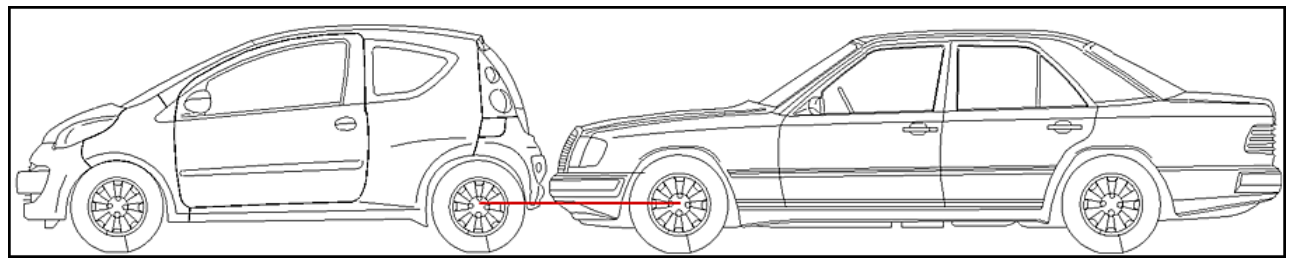

Fig. 6. Comparison of the vehicle bodies.

Energy required to cause deformation of the body of Citroën was estimated on the basis of Equivalent Energy Speed from EES catalogue (http://www.dsd.at) and it was $20 \mathrm{~km} \cdot \mathrm{h}^{-1}$. Dynamic calculations showed that inertial accelerations reached the value of about $6.66 \mathrm{~g}$. The impact scheme is demonstrated in Fig. 7.

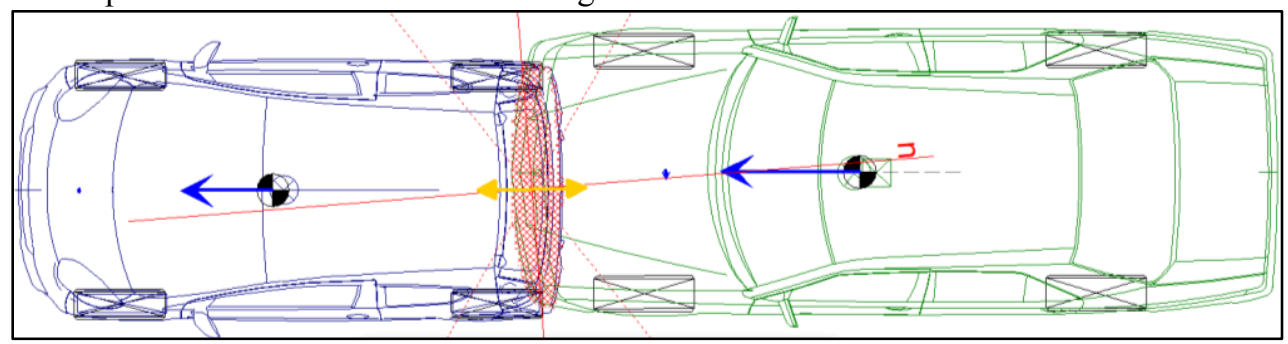

Fig. 7. Collision of Citroën and Mercedes passenger cars.

Below, in Fig. 8, there are time courses of acceleration in axes of a system connected with the vehicle $x, y, z$, and in Fig. 9 there are inertial acceleration changes that affected the driver of Citroën during an accident every $20 \mathrm{~ms}$ - they are represented on the below schemes by red vectors. 


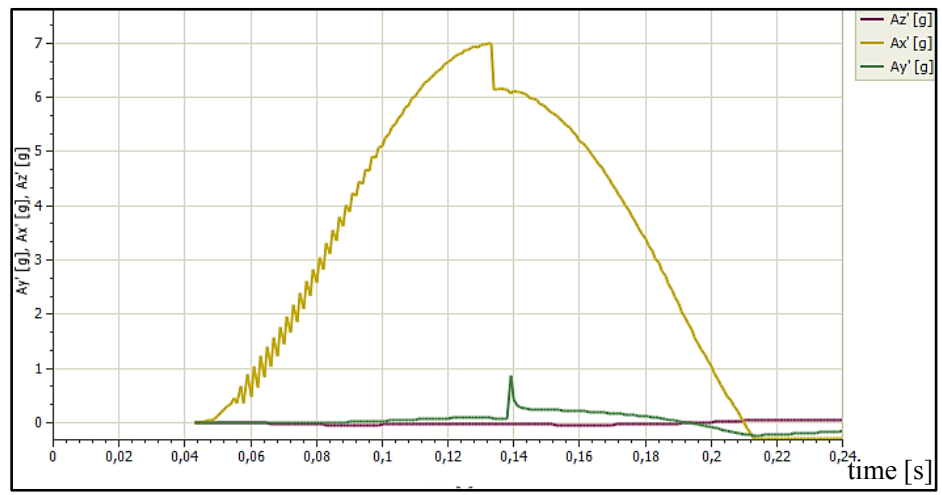

Fig. 7. Change in inertial accelerations in a function of time.

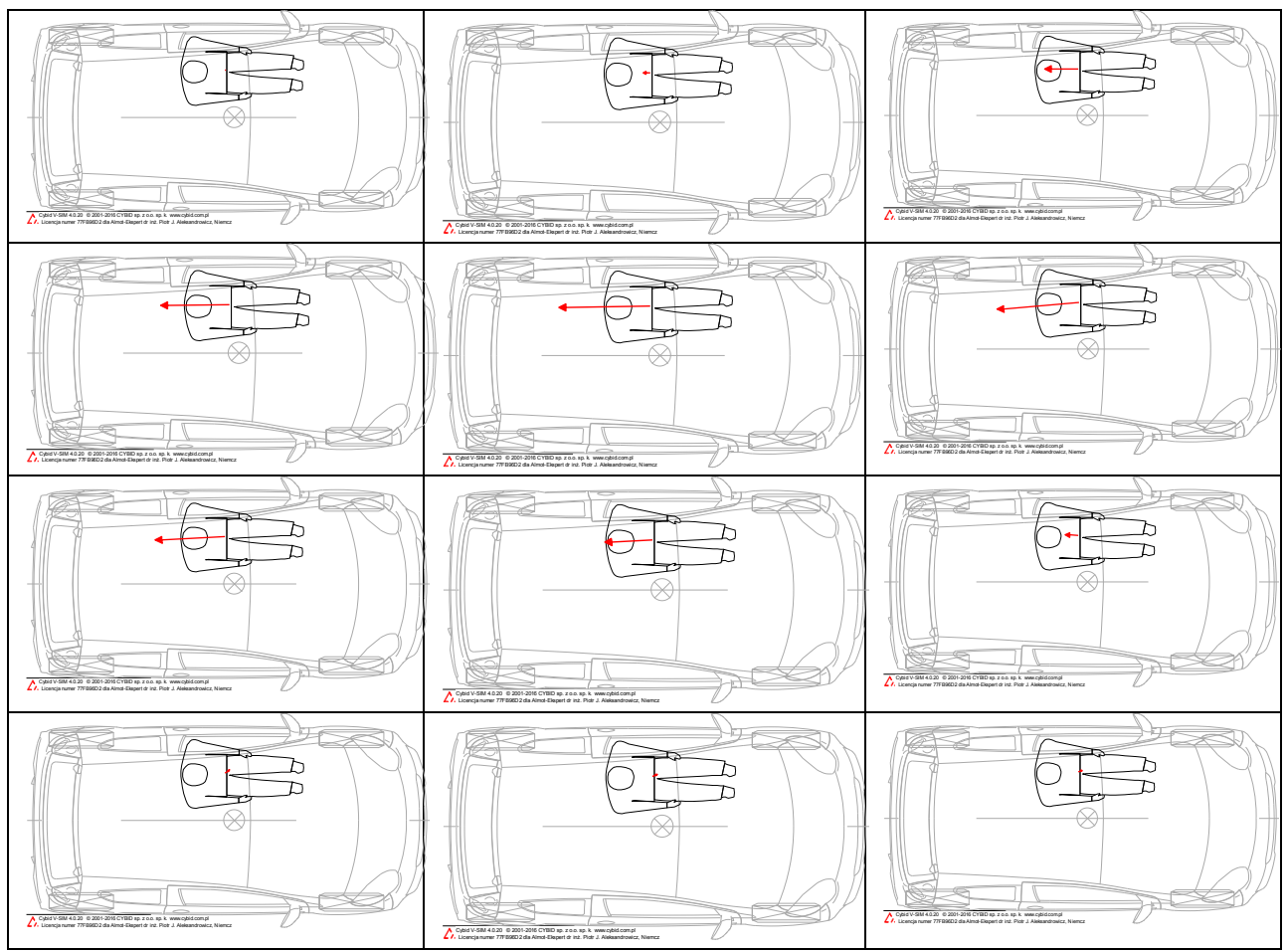

Fig. 8. Direction changes in inertial accelerations.

\section{Conclusions}

The tests have revealed the following:

$>$ the body of the driver of Citroën was affected by inertial accelerations in a very short time, from the impact until culmination is $80 \mathrm{~ms}$, reaching the value of about $6.66 \mathrm{~g}$ and in backward direction- hence, reaching a value higher than the boundary one $-3 g$,

$>$ the criteria that need to occur to cause Whiplash injury to the driver of Citroën were met,

$>$ analysis of the impact according to SDC convention makes it possible to efficiently verify consistence of the reported damage was with occurrence of the mechanism that causes Whiplash type of injury. 


\section{References}

1. J. Wicher. Motor vehicles. Car safety and road traffic. WKŁ Warsaw. pp. 125-126, (2004)

2. J. Wicher. Assessement of road traffic, Classification of car collisions. SRTSiRD Warsaw. pp. 142-143, (2006)

3. G. Gulyaev, V. Loginov, N. Kozlov. Method of Designing the Superstructure of the Car Body Based on the Requirements of Low-Speed Collisions. $9^{\text {th }}$ International Scientific Practical Conference on Innovative Technologies in Engineering, Journal of Physics, Conference Series Vol. 1059, Russia, pp. 140-147, (2018)

4. L. Prochowski, J. Unarski, W. Wach, J. Wicher. Automotive vehicles. Basics of road traffic accidents. WKŁ Warsaw. pp. 244-245, (2008)

5. P. Aleksandrowicz. Verifying a truck collision applying the SDC method. $58^{\text {th }}$ International Conference of Machine Design Departments, 6-8.09.2017, Praque, Czech Republic, pp.14-19, (2017)

6. J. Zalewski. Selected problems of motor vehicle maintenance after side impact collision. MATEC Web Conf. Paper No. 01019 182, (2018)

7. R. Kostek, P. Aleksandrowicz. Simulation of car collision with an impact block. $11^{\text {th }}$ International Congress of Automotive and Transport Engineering, 8-10.11.2017 Pitesti, Romania, (2017)

8. R. Kostek, P. Aleksandrowicz. Simulation of the right-angle car collision based on identified parameters. $11^{\text {th }}$ International Congress of Automotive and Transport Engineering, 8-10.11.2017 Pitesti, Romania, (2017)

9. P. Aleksandrowicz, R. Kostek. Study of vehicle crashes into a rigid barrier. Transactions of the Canadian Society for Mechanical Engineering, (2019)

10. P. Aleksandrowicz. The impact of a vehicle braking system state on safe driving - part one. $17^{\text {th }}$ International Conference Diagnostic of Machines and Vehicles, 1920.09.2018, Pieczyska, Poland, MATEC Web Conf. vol. 182, 01025, (2018)

11. P. Aleksandrowicz. The impact of a vehicle braking system state on safe driving - part two. $10^{\text {th }}$ International Scientific Session Applied Mechanics, 23.11.2018, Bydgoszcz, Poland, AIP Conference Proceedings 2-77, 020001, (2019)

12. K. Brösdorf, M. Görtz. Gefahren oder gestanden? Tagungsband des $23^{\text {rd }}$ EVU Jahrestagung. pp.1-6, (2014) 